Article

\title{
Field Evaluation of Synthetic Polymer Rubber Gel through Filler Content and Oil Leakage Mass Measurement
}

\author{
Jin-sang Park ${ }^{1}$, Dong-bum Kim ${ }^{1}$, Kyu-hwan $\mathrm{Oh}^{2}$ and Sang-keun $\mathrm{Oh}^{3, *}$ \\ 1 Program of Architecture of Convergence Institute of Biomedical Engineering and Biomaterials of Graduate \\ School, Seoul National University of Science and Technology, 232 Gongneung-ro, Nowon-gu, \\ Seoul 01811, Korea; sciencewater@naver.com (J.-s.P.); db2128@naver.com (D.-b.K.) \\ 2 Department of Railway Construction Engineering, Graduate School of Railway, Seoul National University of \\ Science \& Technology, 232 Gongneung-ro, Nowon-gu, Seoul 01811, Korea; kyuhwan.oh@seoultech.ac.kr \\ 3 School of Architecture, Seoul National University of Science \& Technology, 232 Gongneung-ro, Nowon-gu, \\ Seoul 01811, Korea \\ * Correspondence: ohsang@seoultech.ac.kr; Tel.: +82-2-970-6559
}

Received: 22 March 2018; Accepted: 23 May 2018; Published: 30 May 2018

\begin{abstract}
Synthetic Polymer Rubber Gels (SPRG) are used in Composite Modified Bituminous Waterproofing $(\mathrm{CMBW})$ systems for waterproofing in concrete structures. A problem with the current design of SPRG is that when the emulsion breaks, the segregated oil layer can percolate through concrete cracks and cause oil leakage. This study proposes a new evaluation method which assesses the practical performance of SPRG products by testing their susceptibility to filler content settlement and oil leakage. Eight SPRG products used in Korea were used to demonstrate this evaluation method. Each product was installed in a concrete substrate specimen with an artificial crack made in the specimen's bottom substrate. The specimens were observed for 28 days, and mass of leaked oil, total duration of leakage, average rate of sedimentation, and rheological threshold of initial leakage point were examined as part of the evaluation criteria.
\end{abstract}

Keywords: modified bituminous sheet; Synthetic Polymer Rubber Gel; filler content settlement; composite bituminous waterproofing method; waterproofing material

\section{Introduction}

\subsection{Research Background and Objectives}

Due to the rise of below-grade concrete structure construction, East Asian nations are developing composite waterproofing systems comprising multiple types of materials. These systems generally have a higher performance level than contemporary single-ply coating or sheet-based waterproofing systems [1]. For example, in below-grade structures, soil pressure and intermittent structural movement can cause deterioration of waterproofing layers, so composite waterproofing systems are considered essential for securing long-term durability [2].

Single-ply membranes such as sheet or liquid coating are relatively easier to install, but require specific thermal and/or humidity conditions for proper adhesion. The overlapping sections can form defects as well [3]. For liquid coating membranes, achieving an even thickness is difficult and improper installation can lead to deformations such as blistering or air pockets [4].

There are 3 common types of composite waterproofing systems. Each system comprises a waterproofing sheet with a base coating or membrane type, and a modified bituminous sheet with a Synthetic Polymer Rubber Gels (SPRG) layer; a modified bituminous sheet (or PVC sheet) with liquid 
coating (Urethane, etc.) membrane layer; or a modified bituminous sheet with a polymerized rubber sealant membrane layer. These systems are designed to (1) naturally recover from deformations from concrete crack/joint movements (shear and tensile stress) and (2) provide resistance to hydrostatic pressure and compressive loads [5]. A detailed illustration of each system is shown below in Figure 1.

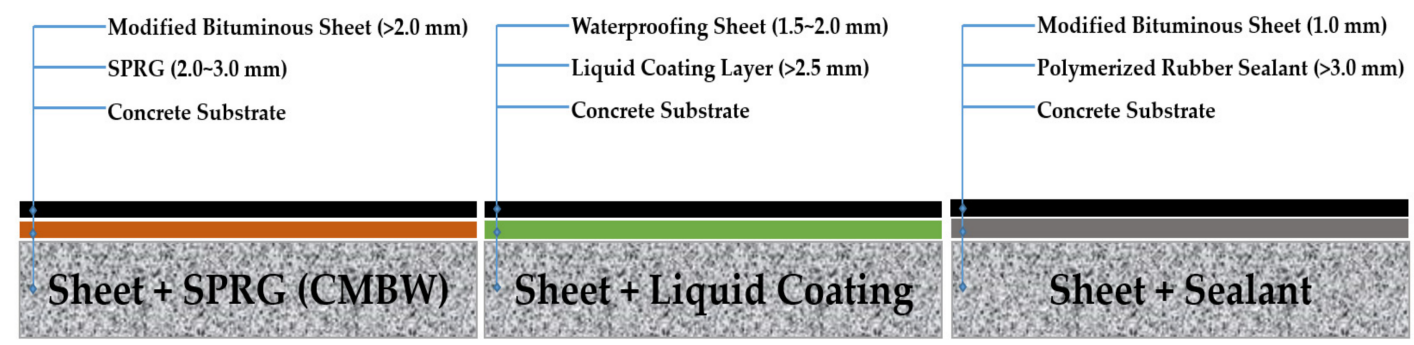

Figure 1. Structural models of different composite waterproofing systems. SPRG, Synthetic Polymer Rubber Gels; CMBW, Composite Modified Bituminous Waterproofing.

\subsection{Problems Concerning CMBW System Application as Waterproofing in Concrete Structures}

SPRG are susceptible to filler content settlement where admixture contents and oil layers are segregated by naturally occurring emulsion breaking processes [6]. The rheological property of the segregated oil allows the oil to pass through micro-sized cracks in concrete substrates [7]. Under normal circumstances, properly manufactured SPRG have no risk of oil leaking through the cracks. However, many manufacturers modify the mixture ratios from those of standard SPRG to reduce cost [8]. Furthermore, Composite Modified Bituminous Waterproofing (CMBW) systems using SPRG are relatively new and difficult to assess in the general SPRG manufacturing process; storage and transport conditions, handling before and during construction, and workmanship all lack a clear standard [9]. In an attempt to address these issues and prevent the production of unstable SPRG products, this study introduces a new evaluation method which better takes into account the field conditions of concrete structures.

\section{Oil Leakage Mechanism of SPRG in CMBW Systems}

\subsection{Oil Leakage Phenomenon of SPRG Used as Waterproofing in Concrete Structures}

SPRG is a polymer-modified bitumen emulsion designed specifically for waterproofing in below-grade concrete structures. Bituminous emulsion consists of bitumen particles dispersed in a solvent base where particles form larger agglomerates via binders. Ideally, admixtures are mixed in correct ratios, the bitumen emulsion maintains a stable structure, and similar-sized particles are distributed evenly throughout the emulsion base [10]. However, most bitumen emulsions have crosslinks that are Van der Waal type bonds, and may undergo a breaking or creaming process in the middle of coalescence or flocculation [11]. This leads to sedimentation of the filler contents and segregation of different components of the emulsion due to difference in density [12]. Refer to Figure 2 for an illustration.

Unlike other types of rubberized bitumen emulsions, SPRG polymers do not completely crosslink. This is intentionally done so as to provide a high resistance to zero-span tensile stress during substrate movement [13]. Standard SPRG straight out of manufacturing quarries have high viscosity and are difficult to work with. Product designers focus on achieving high workability by compromising long-term emulsifying stability and straying from standard mix designs [14]. This is largely due to an absence of regulation and standardized evaluation criteria to control the quality of SPRG. 


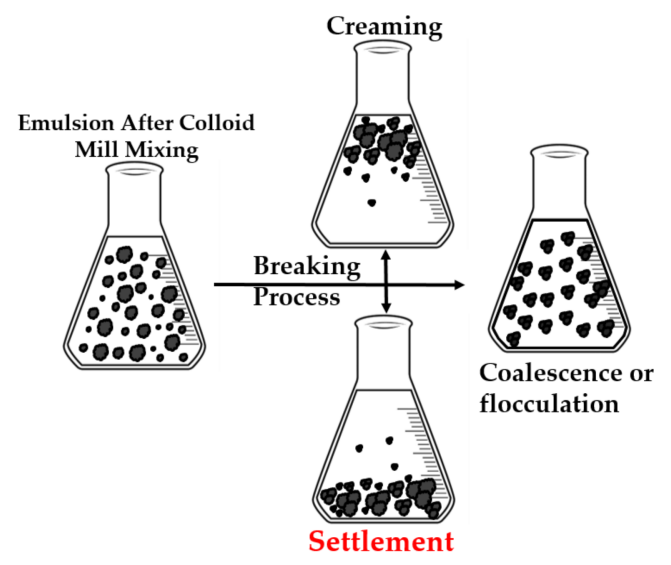

Figure 2. Illustration of SPRG breaking stages.

Before an SPRG product is selected for usage in concrete structures, information on expected oil leakage mass should be accessible to assess the potential risks to the structure [14]. Eventually, natural sedimentation of filler contents forms finely distributed layers within the SPRG membranes, with the topmost layer (oil layer from emulsion breaking) having the highest rheological activity with lowest filler content concentration. When a crack or joint forms in the concrete substrate, structural movement and compression cause the oil layer to leak through the micro-sized cracks, resulting in leakage through the concrete crack or joint. Refer to Figure 3 for details.

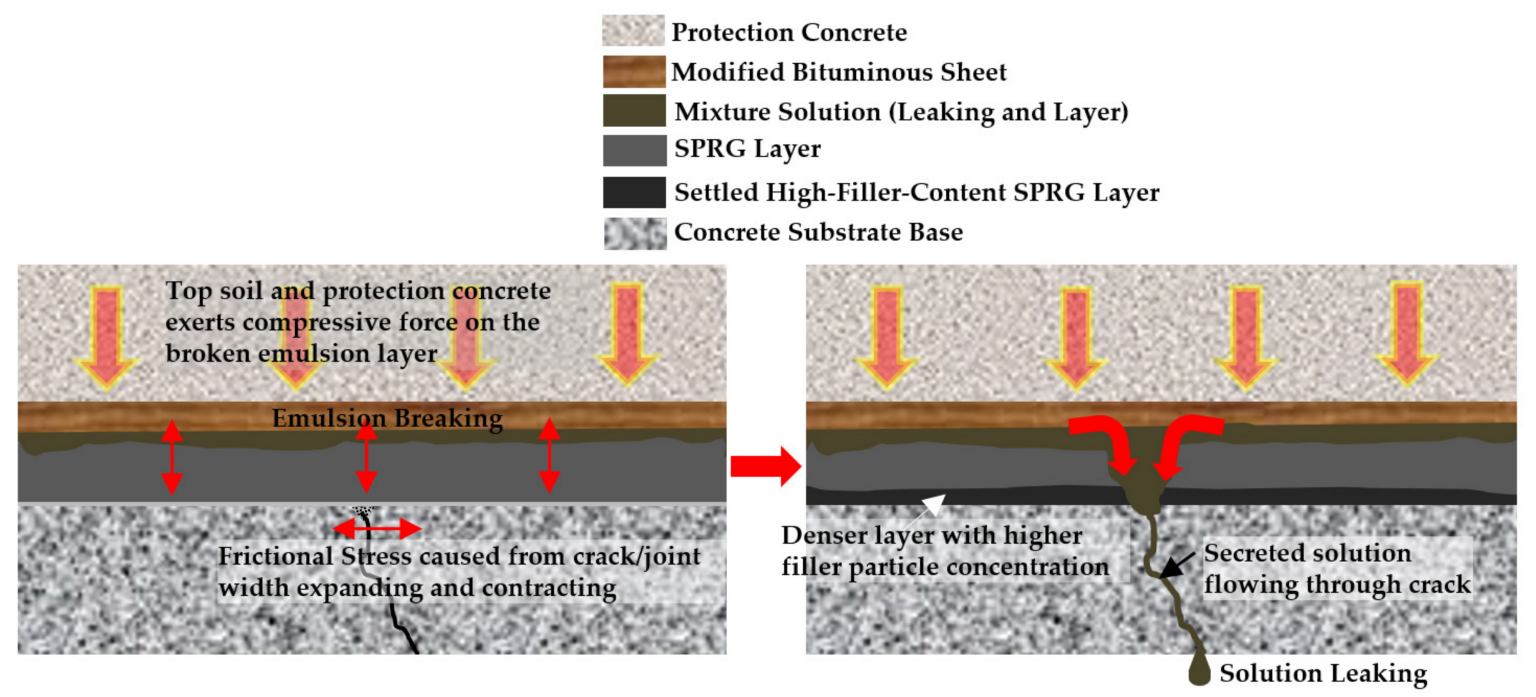

Figure 3. Oil leakage mechanism of SPRG-based CMBW, illustrated.

\subsection{Existing Standard Evaluation Methods and Limitations}

There are national standard test methods such as British Standard European Norm (BS EN) and American Society for Testing and Materials (ASTM) designed to test the materials based on the viscosity and settlement tendency of bitumen emulsions. While empirical data obtained from these test methods can provide a detailed understanding of the materials, it does not provide enough information on their practical performance with respect to waterproofing concrete structures. For example, ASTM D 2170 Standard Test Method for Kinematic Viscosity of Asphalts (Bitumen) [15] evaluates the time required for a fixed volume of a bitumen sample to vertically flow through containers linked by narrow capillaries, where kinematic viscosity is calculated by multiplying the efflux time in seconds by the viscometer calibration. This method can provide empirical data on the rheological property of SPRG based on 
the diameter sizes of the tube, and SPRG manufacturers test their materials in compliance with these standard test methods to validate their products' performance. However, actual concrete structures have complex degradation environmental factors, and laboratory experimentation has limitations in accurately simulating these conditions. As illustrated in Figure 3, the compressive force from the protective concrete layer and top soil will cause the segregated oil layer to migrate through an opening and leak through a crack. Unless the below-grade environment is simulated in the experiment and only standard methods are used, an accurate assessment of SPRG oil leakage tendency may be difficult [16].

\section{Materials: SPRG in a Composite Modified Bituminous Waterproofing (CMBW) System}

Refer to Table 1 for a typical composition of SPRG used in Korea.

Table 1. Typical composition of SPRG used for waterproofing.

\begin{tabular}{|c|c|c|c|c|}
\hline Co & osition & Component Types & Specific Gravity (g/mL) & Remarks \\
\hline \multirow{3}{*}{ Solids } & $\begin{array}{l}\text { Rubber and } \\
\text { Bitumen }\end{array}$ & $\begin{array}{c}\text { Binders (Bitumen) } \\
\text { Process oil (liquid type) } \\
\text { Natural rubber latex }\end{array}$ & $\begin{array}{c}1.03 \\
0.977 \\
0.921\end{array}$ & $\begin{array}{l}\text { Organic } \\
\text { additives }\end{array}$ \\
\hline & \multirow{2}{*}{ Fillers } & $\begin{array}{l}\text { Calcium carbonate compound } \\
\text { (powder type) }\end{array}$ & 2.71 & \multirow{2}{*}{$\begin{array}{l}\text { Inorganic } \\
\text { additives } \\
\text { (fillers) }\end{array}$} \\
\hline & & $\begin{array}{c}\text { Natural minerals (powder type) } \\
\text { Other additives }\end{array}$ & $\begin{array}{l}2.12 \\
1.02\end{array}$ & \\
\hline \multicolumn{2}{|c|}{ Solvent } & $\begin{array}{l}\text { Emulsion solvent base, and other } \\
\text { additives to stabilize emulsion }\end{array}$ & $9.3 \sim 1.00$ & $\begin{array}{l}\text { Water, chemical } \\
\text { agents, etc. }\end{array}$ \\
\hline
\end{tabular}

For this study, 8 different types of Korean SPRG products were selected. Individual SPRG mixture ratios differ in accordance to their own manufacturing methods. Each of the SPRG samples were tested for their viscosity and basic composition. Each sample's viscosity was measured in compliance with the method outlined in KS M ISO 2555: 2002 with a Brookfield viscometer, and the general composition ratio was measured in compliance with KOREA LAND \& HOUSING CORPORATION 42531: 2015. Refer to Table 2 below for details.

Table 2. Details of product (specimen) properties of viscosity and composition ratio.

\begin{tabular}{ccccc}
\hline & & \multicolumn{3}{c}{ Composition (\%) } \\
\cline { 3 - 5 } Sample & $\begin{array}{c}\text { Viscosity (cps) } \\
\left(\mathbf{2 0}{ }^{\circ} \mathbf{C} \text {, Sp. } \mathbf{~}\right)\end{array}$ & \multicolumn{2}{c}{ Solids } & Water Content \\
\cline { 3 - 5 } & & $\begin{array}{c}\text { Filler Content } \\
(\boldsymbol{p}) * \mathbf{1}\end{array}$ & $\begin{array}{c}\text { Rubber and } \\
\text { Bitumen }\end{array}$ & $\begin{array}{c}\text { Water and Chemical } \\
\text { Additives }\end{array}$ \\
\hline A & 346,000 & 25.8 & 52.2 & 22 \\
B & 430,333 & 22.7 & 55.1 & 22.2 \\
C & 346,000 & 25.5 & 51.2 & 23.3 \\
D & 954,000 & 27.4 & 58.7 & 13.9 \\
E & 718,000 & 25.8 & 55.8 & 18.4 \\
F & 822,000 & 28.3 & 61 & 10.7 \\
G & 393,000 & 24.6 & 48 & 27.4 \\
H & 480,000 & 27.1 & 47.7 & 25.2 \\
\hline
\end{tabular}

${ }^{* 1}$ Filler content in original state $(p)$ will be used during the evaluation process.

\section{Preparation of Test Specimens for the New Proposed Evaluation Method}

For installing the CMBW systems, an SPRG sample with constant mass of $150 \mathrm{~g}$ was used. For other procedures, manufacturer instructions were followed while accounting for risks of faulty workmanship. Specimens were assembled under normal laboratory conditions, with temperature at $20 \pm 3{ }^{\circ} \mathrm{C}$, and relative humidity of $60 \pm 5 \%$. Table 3 illustrates and describes the components in detail. 
Table 3. Test specimen structure and component description and illustration.

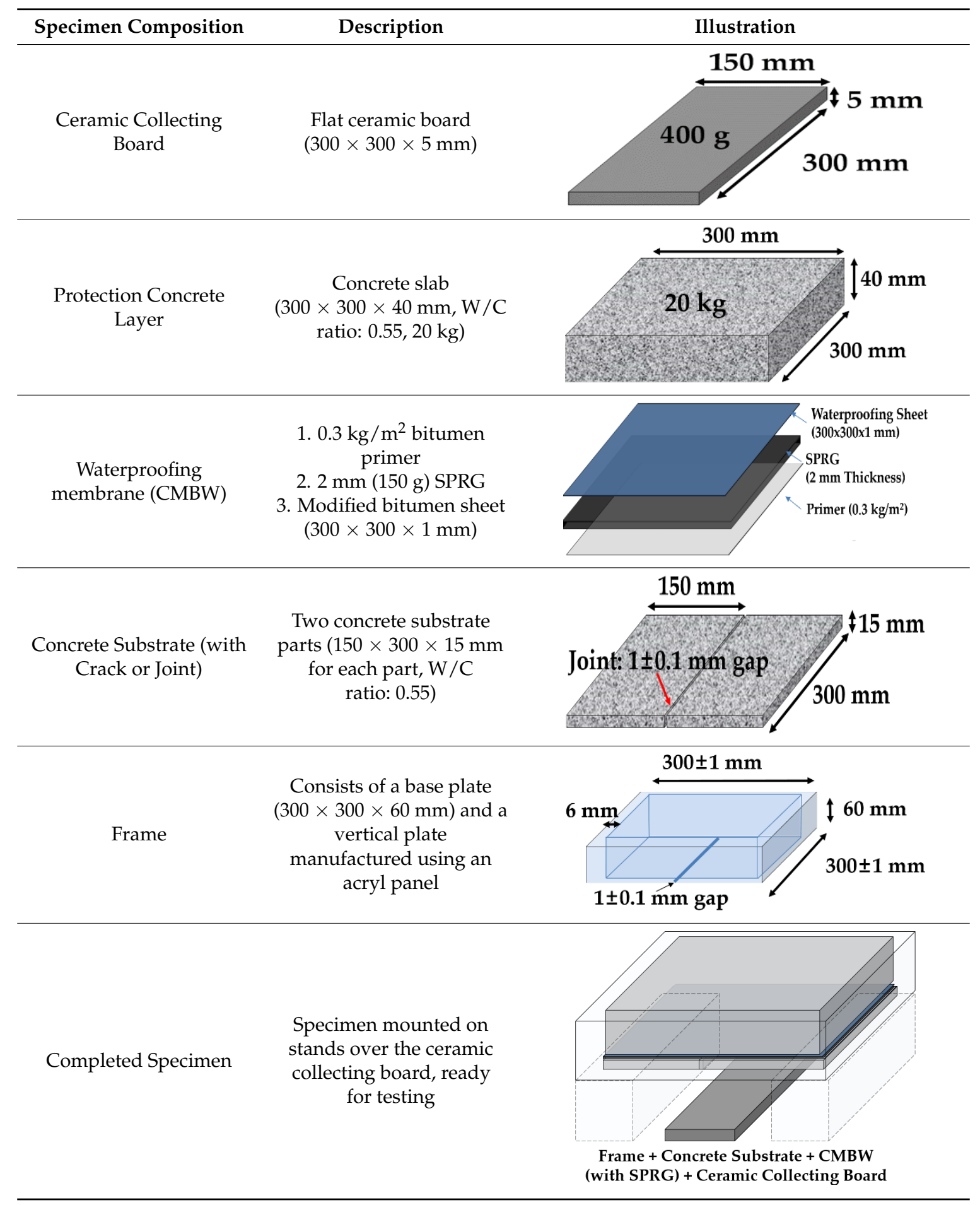

Two concrete substrate parts were placed side by side inside the frame, with a $1 \pm 0.1 \mathrm{~mm}$ separation gap forming in between. Approximately $0.3 \mathrm{~kg} / \mathrm{m}^{2}$ bitumen primer was applied (and dried for $6 \mathrm{~h}$ ) using a brush on the concrete substrate parts. Next, a $2 \mathrm{~mm}$ thick SPRG layer was installed using a metal spatula. The modified bitumen sheet was installed on the SPRG layer. Lastly, the protection concrete was placed over the installed CMBW system. The completed specimen was mounted on stands, and the ceramic collecting board (alternate collecting device/containers can be 
used) was placed directly below, perpendicular to the gap of the specimen. Refer to Table 4 for an illustration of the specimen assembly procedure.

Table 4. Specimen assembly procedure (illustrated).

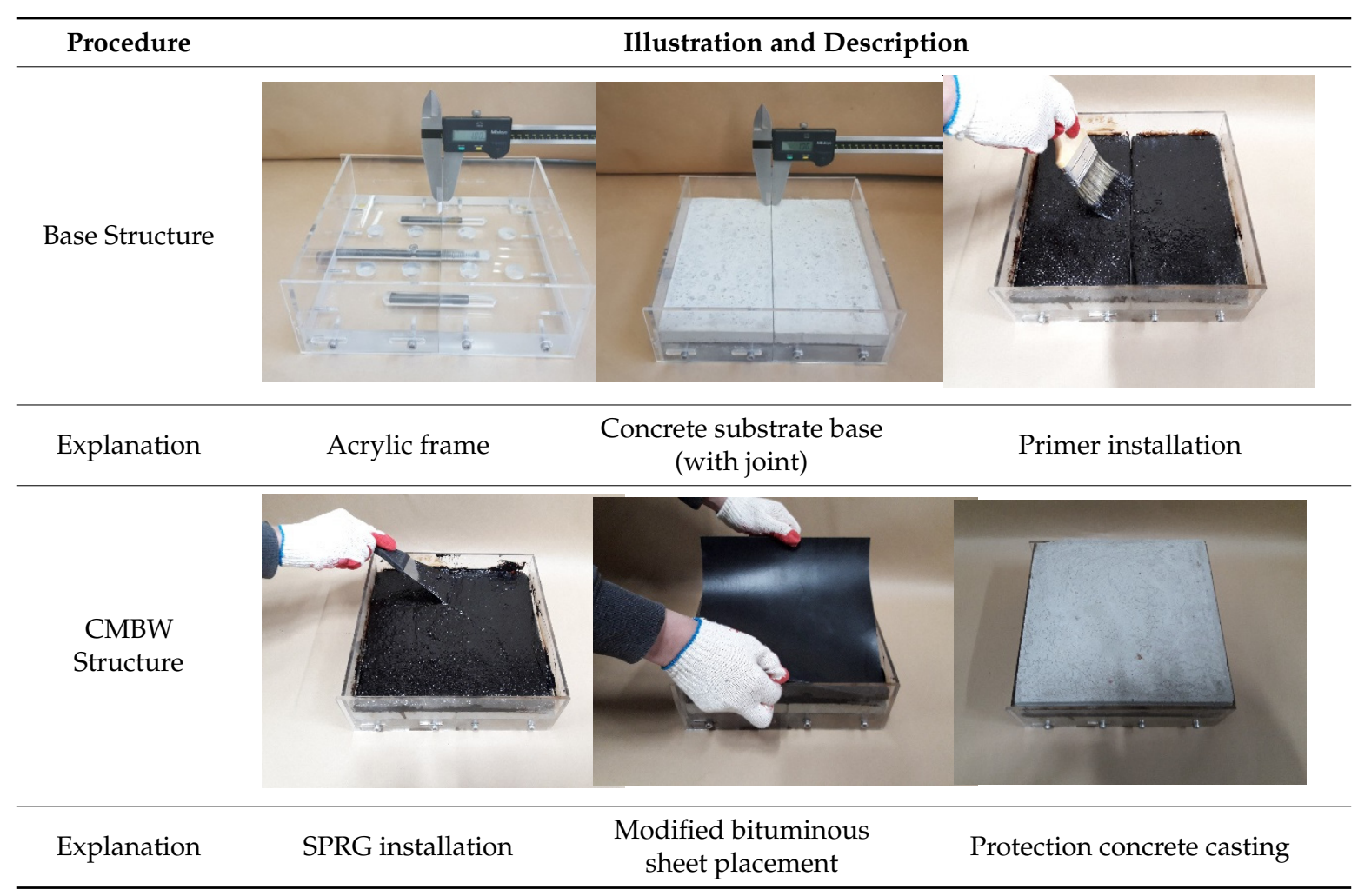

\section{Testing Methods for the New Proposed Evaluation Method (Demonstration)}

The evaluation method is divided into two steps; (1) measurement of the leaking oil based on duration and mass; and (2) filler content measurement of the leaked oil. The following sections cover each step in detail.

\subsection{Total Oil Leakage Mass Measurement}

Three separate specimens were prepared for each of the 8 SPRG products (refer to Table 2). Each fully assembled specimen was set to rest in an ambient setting with $20 \pm 3{ }^{\circ} \mathrm{C}$ temperature and $65 \pm 20 \%$ humidity. Two sets of 2 mortar blocks (each $300 \mathrm{~mm} \times 50 \mathrm{~mm} \times 40 \mathrm{~mm}$ ) were placed underneath the specimen parallel to each other, leaving an opening directly underneath the gap of the concrete block. Below the opening, a ceramic collecting board was placed perpendicular to the gap on the acrylic frame. Each specimen was evaluated for a period of 28 days in ambient conditions compliant with KS standards. During this period, the ceramic collecting board was checked daily for oil leakage. When leakage drops were found, the ceramic collecting board was replaced and the oil leakage on the old board was weighed on a scale. The mass of the oil leakage sample (g) from the specimen was measured down to two decimal points. At the end of the testing period, the total mass of the oil leakage was derived. An illustration of this procedure is outlined below in Figure 4 . 


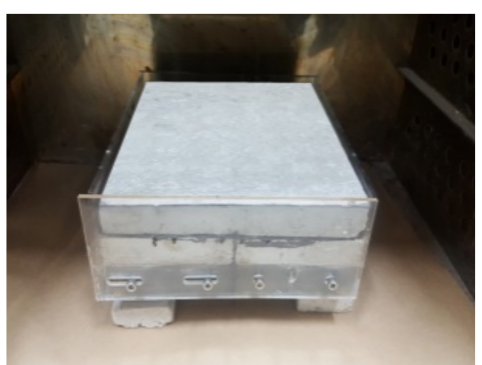

(a)

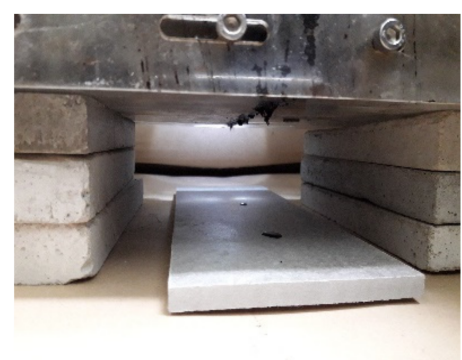

(b)

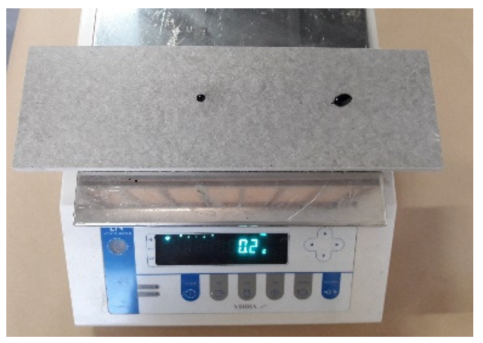

(c)

Figure 4. SPRG leaking demonstration and filler content settlement evaluation procedure; (a) specimen placement; (b) leakage observation; (c) oil leakage mass measurement.

\subsection{Filler Content of Oil Leakage Measurement}

For each of the daily collected samples, filler content was measured while following the KOREA LAND \& HOUSING CORPORATION 42531: 2015 Standard. The ceramic collecting board with the oil leakage sample was placed in a desiccator with the temperature set to $105 \pm 5^{\circ} \mathrm{C}$ until the material reached constant mass. The specimen was then placed in an electric furnace at a temperature ranging from 900 to $1000{ }^{\circ} \mathrm{C}$. The mass of the residues (filler content) remaining was calculated once the sample reached constant mass, and cooled in the desiccator (set to $20 \pm 3^{\circ} \mathrm{C}$ and $65 \pm 20 \%$ humidity). The mass is calculated using the following formula:

$$
\mathrm{F}_{\mathcal{C}}(\text { mass, } \%)=\left(\mathrm{W}_{3}-\mathrm{W}_{1}\right) /\left(\mathrm{W}_{2}-\mathrm{W}_{1}\right) \times 100(\%)
$$

where

- $\mathrm{F}_{c}$ : the percentage of the measured filler content;

- $\mathrm{W}_{1}$ : the mass of the ceramic collecting board;

- $\mathrm{W}_{2}$ : the mass of the ceramic collecting board and the procured oil leakage specimen;

- $\mathrm{W}_{3}$ : the mass of the ceramic collecting board after placement in a high-temperature electric furnace.

\subsection{Evaluation Criteria}

The proposed evaluation method assesses the performance of SPRG while simulating the field conditions of concrete structures as closely as possible. The leakage duration over a predetermined evaluation period and the (1) oil leakage mass were observed. Next, the overall averages of the filler content settlement were measured throughout the 28 days of the evaluation period and (2) at the initial leakage (IL) day to provide a criterion for relative comparison of emulsifying stability.

\subsubsection{Leakage Duration (Collective Number of Leakage Day Intervals)}

The intervals of days during which oil was detected is recorded. This criterion is evaluated using the following equation, hereinafter labelled as Equation (1):

$$
t_{3}-t_{2}=t_{1}
$$

where

- $t_{1}$ : the collective number of days when leakage was detected;

- $t_{2}$ : the collective number of days when leakage was not detected;

- $t_{3}$ : the predetermined period for the evaluation (for the demonstration, 28 days was selected). 


\subsubsection{Cumulative Leakage Mass}

The cumulative amount of the leaked oil substance is measured. This criterion is evaluated using the following equation, hereinafter labelled as Equation (2):

$$
m_{1}+m_{2}+m_{3}+m_{4}+m_{5}+\ldots=l
$$

where

- $\quad m_{i}$ : the amount of leaked oil from the SPRG in specific daily interval $i$;

- $l$ : the cumulative amount of leaked oil at the end of the predetermined testing period (for the demonstration, 28 days was selected).

\subsubsection{Average Filler Content Measurement of Leaked Samples}

An estimation of the settlement rate is derived based on the change in the filler content in the leaked oil samples. This criterion is evaluated using the following equation, hereinafter labelled as Equation (3):

$$
h / p \times 100(\%)=f
$$

where

- $h$ : average of the respective filler content percentages of oil leak samples during the testing period;

- $\quad p$ : filler content percentage of the original sample (provided in Table 2);

- $f_{\mathrm{a}}$ : average percentage difference of the filler content of the oil layer and the original filler content over the evaluation period.

\subsubsection{Average Filler Content at Initial Leakage (IL) Day}

The point during the filler content settlement at which the segregated oil has sufficient rheological property to flow through the minute-sized openings and cracks. This criterion is evaluated using the following equation, hereinafter labelled as Equation (4):

$$
r / p \times 100(\%)=f_{\mathrm{i}}
$$

where

- $\quad r$ : filler content percentage of the oil leak sample in the IL day interval;

- $\quad p$ : filler content percentage of the original sample (provided in Table 2);

- $f_{\mathrm{i}}$ : estimated percentage of the minimum filler content of the oil layer in the SPRG to achieve the rheological state to leak through the concrete cracks.

\section{Evaluation Results}

During the 28 days of evaluation, 6 out of the 8 products were shown to leak oil. For each of the 18 specimens (3 specimens for the 6 defective products), further evaluation was conducted in two stages: (1) evaluation of leakage mass and duration; and (2) measurement of filler content percentage.

\subsection{Evaluation of Oil Leakage Mass and Duration (Number of Leakage Day Intervals)}

Six (Samples A, B, C, D, E, and G) out of the eight specimens were found with filler content settlement and leaked oil. Although the testing period was set to 28 days, none of the specimens leaked oil past the 25th day, so results from past the 25th day are not displayed. At the end of the evaluation period, the respective daily masses of the oil leak were summed up, and an average of the leakage mass between 3 specimens of each product was derived. The details are shown below in Table 5 . 
Table 5. Cumulative Measurement of Oil Leakage Mass over Evaluation Period (Days Leaked).

\begin{tabular}{|c|c|c|c|c|c|c|c|c|c|c|c|c|c|c|c|c|c|c|c|c|c|c|c|c|c|c|c|c|c|}
\hline \multicolumn{2}{|c|}{$\begin{array}{c}\text { Days } \\
\text { Sample }\end{array}$} & 1 & 2 & 3 & 4 & 5 & 6 & 7 & 8 & 9 & 10 & 11 & 12 & 13 & 14 & 15 & 16 & 17 & 18 & 19 & 20 & 21 & 22 & 23 & 24 & 25 & Mass (g) & $\begin{array}{c}\text { Avg. }(l) * 1 \\
\text { (g) }\end{array}$ & $\begin{array}{l}\text { No. Days } \\
\left(t_{1}\right)^{* 2}\end{array}$ \\
\hline \multirow{3}{*}{ A } & 1 & $x$ & $x$ & 0.35 & 0.21 & 1.25 & 2.16 & 1.37 & $X$ & 1.23 & 1.65 & $x$ & 1.73 & 0.91 & 1.18 & 3.71 & 1.32 & 1.86 & 2.57 & $X$ & 1.13 & $x$ & $x$ & $x$ & $x$ & $x$ & 22.68 & \multirow{3}{*}{20.65} & 15 \\
\hline & 2 & $x$ & $x$ & 0.21 & 1.82 & 0.91 & 1.39 & 2.11 & 1.78 & 2.52 & 3.15 & 1.21 & 0.87 & 1.62 & 0.72 & $X$ & 0.54 & 0.38 & $X$ & 0.52 & 0.17 & $x$ & $X$ & $x$ & $x$ & $x$ & 19.92 & & 16 \\
\hline & 3 & $x$ & $x$ & $X$ & 0.51 & 0.79 & 1.21 & 3.27 & 2.46 & 1.56 & 2.13 & 1.39 & 2.52 & $x$ & 1.57 & $X$ & 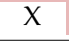 & 0.54 & 0.38 & 0.88 & $X$ & $x$ & 0.13 & $x$ & $x$ & $x$ & 19.34 & & 14 \\
\hline \multirow{3}{*}{ B } & 1 & $x$ & 0.69 & 0.42 & 0.73 & 0.35 & 0.47 & $x$ & $X$ & 0.52 & $X$ & 0.72 & 0.33 & $x$ & 0.81 & 0.85 & 0.93 & 0.62 & 0.43 & $X$ & $x$ & $x$ & $x$ & $x$ & $x$ & $x$ & 7.87 & \multirow{3}{*}{9.12} & 13 \\
\hline & 2 & $x$ & 0.32 & $X$ & 0.27 & 0.61 & 0.33 & 0.84 & 0.16 & $X$ & $x$ & 0.63 & $X$ & 1.27 & 2.65 & 1.97 & 0.63 & $X$ & $X$ & $X$ & $x$ & $x$ & $x$ & $x$ & $x$ & $x$ & 9.68 & & 11 \\
\hline & 3 & $X$ & 0.75 & 0.29 & 0.53 & 0.45 & $\mathrm{X}$ & 0.48 & 0.39 & $x$ & 0.78 & 1.23 & 0.74 & $\mathrm{X}$ & 0.45 & 1.67 & 1.02 & 0.28 & 0.44 & 0.31 & $X$ & $x$ & $x$ & $x$ & $x$ & $x$ & 9.81 & & 15 \\
\hline \multirow{3}{*}{ C } & 1 & $x$ & $x$ & $x$ & $x$ & $x$ & 0.63 & 1.34 & 0.97 & 1.25 & $x$ & 1.03 & 0.82 & 0.76 & $x$ & 1.56 & 1.12 & 0.57 & $X$ & 0.83 & $x$ & 0.68 & $X$ & $x$ & $x$ & $x$ & 11.56 & \multirow{3}{*}{12.67} & 12 \\
\hline & 2 & $x$ & $x$ & $x$ & $x$ & $x$ & $X$ & 0.51 & $X$ & 0.36 & 2.16 & 1.43 & $X$ & 0.26 & 0.64 & 0.57 & 1.35 & 1.86 & 1.67 & 0.95 & 0.77 & $X$ & $x$ & $x$ & $x$ & $x$ & 12.53 & & 12 \\
\hline & 3 & $x$ & $x$ & $x$ & $x$ & $x$ & 0.44 & $\mathrm{X}$ & 1.67 & 2.13 & 1.26 & 2.07 & 0.35 & 0.75 & 1.62 & $x$ & 0.63 & 0.21 & 0.76 & 0.59 & 0.47 & 0.66 & 0.31 & $x$ & $x$ & $x$ & 13.92 & & 15 \\
\hline \multirow{3}{*}{ D } & 1 & $x$ & $x$ & $x$ & $x$ & $x$ & $x$ & 0.21 & 0.59 & X & 0.63 & 0.87 & 1.82 & $x$ & 1.25 & 2.64 & 1.17 & 0.16 & 2.63 & $x$ & 0.84 & 2.47 & 1.13 & $x$ & $X$ & 0.21 & 16.62 & \multirow{3}{*}{13.59} & 14 \\
\hline & 2 & $x$ & $x$ & $x$ & $x$ & $x$ & $x$ & $X$ & 0.38 & 0.14 & 0.82 & 1.35 & 1.58 & 1.16 & 0.71 & $X$ & 1.89 & 2.32 & 0.93 & 0.45 & 1.12 & $X$ & $X$ & $x$ & 0.13 & $X$ & 12.98 & & 13 \\
\hline & 3 & $x$ & $x$ & $x$ & $x$ & $x$ & $x$ & $x$ & $x$ & 0.16 & 0.74 & 0.37 & $\mathrm{X}$ & 1.07 & 1.35 & 2.22 & 1.17 & 0.65 & 0.46 & 1.23 & 1.51 & 0.24 & $X$ & $x$ & $x$ & $x$ & 11.17 & & 12 \\
\hline \multirow{3}{*}{ E } & 1 & $x$ & $x$ & $X$ & 1.02 & 0.36 & $X$ & 0.52 & $x$ & 0.27 & $X$ & 0.57 & $x$ & $x$ & 0.33 & 0.68 & $x$ & $x$ & $x$ & 0.26 & 0.19 & $X$ & 0.35 & $X$ & $x$ & $x$ & 4.55 & \multirow{3}{*}{5.64} & 10 \\
\hline & 2 & $x$ & 0.42 & $x$ & 1.23 & $X$ & 0.12 & $X$ & 0.74 & $X$ & 0.52 & 0.17 & $x$ & 0.58 & $X$ & 0.64 & 0.29 & $x$ & 0.17 & $X$ & $X$ & 0.45 & 0.36 & $x$ & 0.27 & $x$ & 5.96 & & 13 \\
\hline & 3 & $x$ & $X$ & $x$ & $X$ & 0.68 & $\mathrm{X}$ & 0.74 & $X$ & 0.83 & 0.26 & $\mathrm{X}$ & $x$ & 0.57 & 0.62 & $\mathrm{X}$ & 0.79 & 1.42 & 0.32 & $x$ & $x$ & 0.18 & $X$ & $x$ & $x$ & $x$ & 6.41 & & 10 \\
\hline \multirow{3}{*}{$F$} & 1 & $x$ & $x$ & $x$ & $x$ & $x$ & $x$ & $X$ & $x$ & $X$ & $x$ & $x$ & $X$ & $x$ & $X$ & $x$ & $x$ & $x$ & $x$ & $x$ & $x$ & $x$ & $x$ & $x$ & $x$ & $x$ & No Leak & \multirow{3}{*}{$\mathrm{N} / \mathrm{L}$} & \\
\hline & 2 & $x$ & $x$ & $x$ & $x$ & $x$ & $x$ & $x$ & $\mathrm{x}$ & $x$ & $x$ & $x$ & $x$ & $x$ & $x$ & $x$ & $x$ & $x$ & $x$ & $x$ & $x$ & $x$ & $x$ & $\mathrm{x}$ & $x$ & $x$ & No Leak & & \\
\hline & 3 & $x$ & $x$ & $x$ & $x$ & $x$ & $\mathrm{x}$ & $x$ & $x$ & $x$ & $x$ & $x$ & $\mathrm{x}$ & $x$ & $\mathrm{x}$ & $X$ & $x$ & $x$ & $x$ & $x$ & $\mathrm{x}$ & $x$ & $x$ & $x$ & $x$ & $x$ & No Leak & & \\
\hline \multirow{3}{*}{ G } & 1 & $x$ & $\mathrm{x}$ & 0.28 & 0.22 & 0.84 & $\mathrm{X}$ & $\mathrm{x}$ & 0.42 & 1.35 & $\mathrm{x}$ & 0.27 & 0.49 & $\mathrm{X}$ & 0.87 & 1.25 & 1.07 & 1.15 & 0.27 & 1.32 & 1.27 & 0.34 & 0.25 & $x$ & $\mathrm{x}$ & $x$ & 11.66 & \multirow{3}{*}{11.83} & 16 \\
\hline & 2 & $x$ & $x$ & $\mathrm{X}$ & 0.36 & $X$ & 0.72 & 0.51 & $X$ & 0.23 & 0.53 & $\mathrm{X}$ & 0.36 & 0.57 & 1.03 & 1.26 & 1.56 & 1.08 & 1.01 & 0.67 & 0.51 & $X$ & 0.12 & $\mathrm{x}$ & $\mathrm{x}$ & $x$ & 10.52 & & 15 \\
\hline & 3 & $x$ & $x$ & 0.53 & $X$ & 0.14 & 0.42 & $\mathrm{X}$ & 0.78 & $\mathrm{X}$ & 1.11 & $x$ & 0.82 & 0.44 & 1.42 & 1.75 & 0.58 & 0.73 & 1.64 & 0.73 & 1.28 & 0.34 & 0.61 & $x$ & $x$ & $x$ & 13.32 & & 16 \\
\hline \multirow{3}{*}{ H } & 1 & $x$ & $x$ & $x$ & $x$ & $x$ & $\mathrm{x}$ & $\mathrm{x}$ & $x$ & $x$ & $x$ & $x$ & $x$ & $x$ & $x$ & $\mathrm{x}$ & $x$ & $x$ & $x$ & $\mathrm{x}$ & $\mathrm{x}$ & $x$ & $x$ & $x$ & $x$ & $x$ & No Leak & \multirow{3}{*}{$\mathrm{N} / \mathrm{L}$} & \\
\hline & 2 & $x$ & $\mathrm{x}$ & $x$ & $x$ & $x$ & $x$ & $x$ & $x$ & $x$ & $x$ & $x$ & $x$ & $x$ & $x$ & $x$ & $x$ & $x$ & $x$ & $\mathrm{x}$ & $x$ & $x$ & $x$ & $x$ & $x$ & $x$ & No Leak & & \\
\hline & 3 & $x$ & $x$ & $\mathrm{x}$ & $x$ & $x$ & $x$ & $x$ & $x$ & $\mathrm{x}$ & $x$ & $x$ & $x$ & $x$ & $x$ & $x$ & $x$ & $x$ & $x$ & $x$ & $x$ & $x$ & $\mathrm{x}$ & $x$ & $x$ & $x$ & No Leak & & \\
\hline
\end{tabular}

Note: $\mathrm{X}$ : No Leakage occurred. ${ }^{* 1}$ : Value derived from Equation $(2){ }^{* 2}$ : Collective number of days when leakage was detected. 
The above data suggests the following: (1) Samples F and H did not display any signs of leakage throughout the evaluation period, indicating the most stable performance out of the evaluated samples; (2) Sample A had the highest mass of leakage over the evaluation period; and (3) Sample E had the lowest mass of leakage. In this regard, the rest of the samples $(D, C, G$, and B in order of highest to lowest mass of cumulative oil leakage) displayed similar ranges of leakage mass.

\subsection{Overall Average and IL Day Filler Content Measurement}

As precise measurement of filler content settlement rate is difficult without destroying the SPRG specimens, a complete assessment of the sedimentation rate cannot be achieved with the proposed evaluation method. For the scope of this testing, the filler content rate of the leaked oil samples was measured as a reference point of the settlement rate by comparing to the original filler content ratio for each specimen (provided in Table 2). On the days where leakage was detected at the same interval between multiple specimens, the filler content was averaged. Their values are represented with the variable $h$ in Equation (3) in Section 5.3.3. Refer to Table 6 for details.

While Specimens C and D did not have the lowest mass of leakage, these two samples had the highest emulsion stability performance. This is because their IL days were later than the other specimens, averaging at the 6th and 7th day, respectively. Samples A, B, E, and G, however, displayed leakage at an earlier point.

\subsection{SPRG Filler Content Settlement Ratio Calculation}

Figure 5 provides a comparative chart that compares the average $(h)$ and IL day $(r)$ filler content (averaged between 3 specimens for each sample from Table 6) to the original filler content $(p)$ of the normal sample provided in Table 2. Refer to Figure 5 for details.

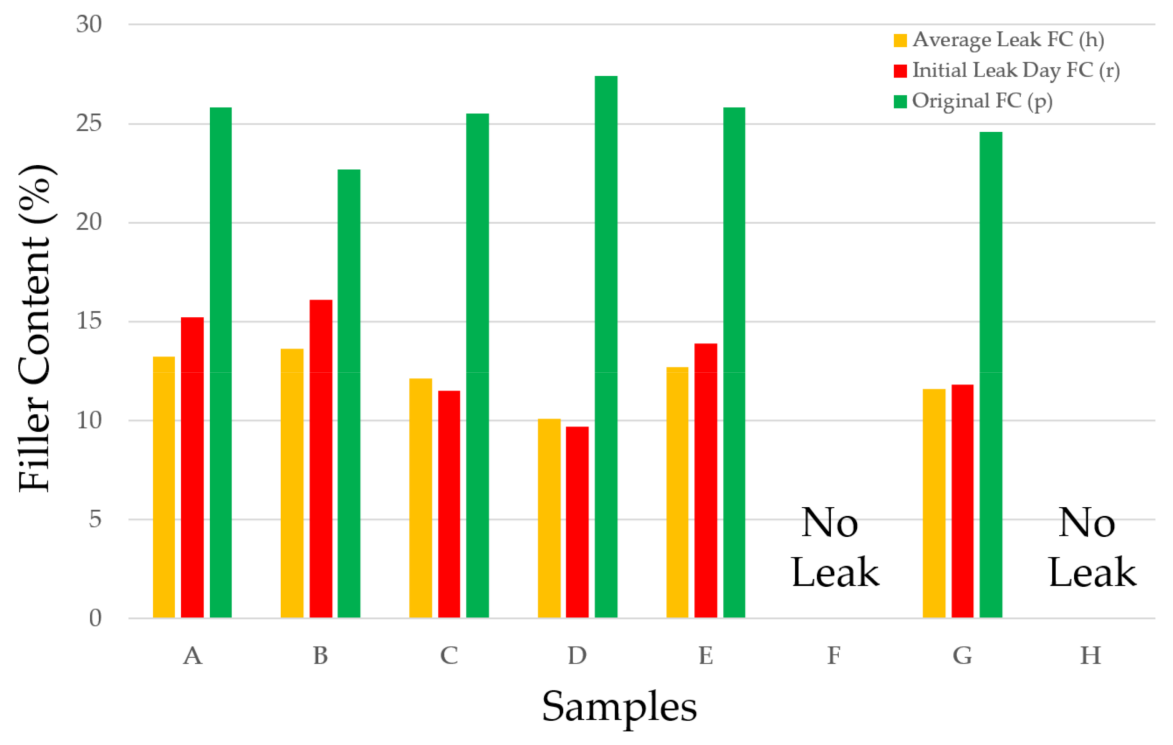

Figure 5. Filler content (FC) comparison of overall average filler content measurement of leaked samples $(h)$, IL day samples $(r)$, and original samples $(p)$.

These values were then calculated as a ratio to the original filler content $\left(f_{\mathrm{a}}\right.$ for overall average derived from Equation (3) from Section 5.3.3 and $f_{\mathrm{i}}$ for IL day derived from Equation (4) from Section 5.3.4). Refer to Table 7 for a detailed outline of the $h$ and $r$ values for each sample followed by the $f_{2}$ and $f_{1}$ values. 
Table 6. Oil Leak Sample Filler Content Measurement (Avg.) over Evaluation Period.

\begin{tabular}{|c|c|c|c|c|c|c|c|c|c|c|c|c|c|c|c|c|c|c|c|c|c|c|c|c|c|c|c|c|}
\hline $\begin{array}{l}\text { Days } \\
\text { Sample }\end{array}$ & 1 & 2 & 3 & 4 & 5 & 6 & 7 & 8 & 9 & 10 & 11 & 12 & 13 & 14 & 15 & 16 & 17 & 18 & 19 & 20 & 21 & 22 & 23 & 24 & 25 & $\begin{array}{l}\text { FC }{ }^{* 1} \text { Avg. } \\
(h)^{* 2}(\%)\end{array}$ & $\begin{array}{l}\mathrm{IL}^{* 3} \mathrm{FC} \\
(r) * 4(\%)\end{array}$ & $\underset{\text { avg.) }}{\text { Days }}{ }^{(t}{ }_{1}$ \\
\hline A & $\mathrm{x}$ & $\mathrm{x}$ & 15.2 & 15.6 & 15.1 & 14.3 & 15.2 & 14.6 & 15.2 & 13.2 & 12.7 & 14.9 & 12.5 & 11.2 & 12.5 & 11.8 & 11.1 & 10.5 & 12.5 & 11.2 & $\mathrm{x}$ & 11.5 & $\mathrm{x}$ & $\mathrm{x}$ & $\mathrm{x}$ & 13.2 & 15.2 & 15 \\
\hline B & $\mathrm{x}$ & 16.1 & 15.2 & 15.6 & 15.1 & 16.2 & 14.2 & 13.6 & 12.2 & 13.6 & 12.5 & 12.8 & 12.1 & 13.2 & 12.3 & 13.2 & 11.5 & 12.5 & 13.3 & $\mathrm{x}$ & $x$ & $x$ & $\mathrm{x}$ & $\mathrm{x}$ & $\mathrm{x}$ & 13.6 & 16.1 & 13 \\
\hline C & $\mathrm{x}$ & $\mathrm{x}$ & $\mathrm{x}$ & $\mathrm{x}$ & $\mathrm{x}$ & 11.5 & 12.2 & 12.7 & 10.8 & 11.1 & 13.2 & 14.6 & 12.5 & 11.8 & 10.5 & 12.5 & 12.6 & 12.3 & 11.5 & 11.6 & 10.6 & 12.6 & $x$ & $\mathrm{x}$ & $\mathrm{x}$ & 12.1 & 11.5 & 13 \\
\hline D & $\mathrm{x}$ & $\mathrm{x}$ & $\mathrm{x}$ & $x$ & $x$ & $\mathrm{x}$ & 9.7 & 10.3 & 11.2 & 9.2 & 9.5 & 9.6 & 11.5 & 11 & 10.6 & 9.6 & 9.2 & 10.7 & 11.2 & 8.5 & 9.2 & 9.3 & $\mathrm{x}$ & 10.6 & 9.2 & 10.1 & 9.7 & 13 \\
\hline E & $\mathrm{x}$ & 13.9 & $\mathrm{x}$ & 13.2 & 13.5 & 14.6 & 13.2 & 13.5 & 14.6 & 13.2 & 12.6 & $\mathrm{x}$ & 12.4 & 12.8 & 13.6 & 13.4 & 14.1 & 12.2 & 13.1 & 11.3 & 12.5 & 11.2 & $\mathrm{x}$ & 11.8 & $\mathrm{x}$ & 12.7 & 13.9 & 11 \\
\hline F & $\mathrm{x}$ & $\mathrm{x}$ & $x$ & $\mathrm{x}$ & $\mathrm{x}$ & $\mathrm{x}$ & $\mathrm{x}$ & $x$ & $x$ & $\mathrm{x}$ & $x$ & $x$ & $x$ & $x$ & $\mathrm{x}$ & $x$ & $x$ & $\mathrm{x}$ & $x$ & $x$ & $\mathrm{x}$ & $\mathrm{x}$ & $\mathrm{x}$ & $\mathrm{x}$ & $\mathrm{x}$ & No Leak & No Leak & No Leak \\
\hline G & $\mathrm{x}$ & $\mathrm{x}$ & 11.8 & 11.6 & 10.4 & 11.7 & 11.9 & 10.2 & 13.2 & 10.4 & 13.8 & 11.5 & 11.3 & 11.4 & 13.6 & 12.5 & 11.4 & 11.3 & 11.8 & 10.3 & 10.5 & 11.3 & $\mathrm{x}$ & $\mathrm{x}$ & & 11.6 & 11.8 & 15.6 \\
\hline H & $\mathrm{x}$ & $\mathrm{x}$ & $\mathrm{x}$ & $\mathrm{x}$ & $\mathrm{x}$ & $\mathrm{x}$ & $\mathrm{x}$ & $\mathrm{x}$ & $\mathrm{x}$ & $\mathrm{x}$ & $\mathrm{x}$ & $\mathrm{x}$ & $\mathrm{x}$ & $\mathrm{x}$ & $\mathrm{x}$ & $\mathrm{x}$ & $\mathrm{x}$ & $\mathrm{x}$ & $\mathrm{x}$ & $\mathrm{x}$ & $\mathrm{x}$ & $\mathrm{x}$ & $\mathrm{x}$ & $\mathrm{x}$ & $\mathrm{x}$ & No Leak & No Leak & No Leak \\
\hline
\end{tabular}

Note: X: No Leakage occurred. ${ }^{* 1}$ : Filler content. ${ }^{* 2}$ : Value used in Equation (3). ${ }^{* 3}$ : Initial Leakage point. ${ }^{* 4}$ : Value used in Equation (4). 
Table 7. Emulsion stability estimation through comparing overall average filler content change $\left(f_{\mathrm{a}}\right)$ and filler content at IL day $\left(f_{i}\right)$.

\begin{tabular}{ccccc}
\hline Samples & $\begin{array}{c}\text { Average Filler } \\
\text { Content }(\boldsymbol{h}) \mathbf{( \% )}\end{array}$ & $\begin{array}{c}\text { IL Day Filler } \\
\text { Content }(\boldsymbol{r})(\boldsymbol{\%})\end{array}$ & $\begin{array}{c}\text { Average Filler Content \% } \\
\text { Difference }\left(f_{\mathrm{a}}\right) \text { (Leaked } \\
\text { Oil/Normal Sample) (\%) }\end{array}$ & $\begin{array}{c}\text { Average Filler Content \% } \\
\text { Difference }\left(f_{\mathrm{i}}\right) \text { (IL Day } \\
\text { Sample/Normal Sample) (\%) }\end{array}$ \\
\hline A & 13.2 & 15.2 & 51.1 & 58.9 \\
B & 13.6 & 16.1 & 59.9 & 70.9 \\
C & 12.1 & 11.5 & 47.5 & 45.1 \\
D & 10.1 & 9.7 & 36.9 & 35.4 \\
E & 12.7 & 13.9 & 49.2 & 53.8 \\
F & No Leak & No Leak & No Leak & No Leak \\
G & 11.6 & 11.8 & 42.8 & 43.5 \\
H & No Leak & No Leak & No Leak & No Leak \\
\hline
\end{tabular}

The average filler content ratio of IL day samples $\left(f_{\mathrm{i}}\right)$ represents the minimum filler content settlement ratio at which leakage begins. The overall average filler content throughout the evaluation period $\left(f_{a}\right)$ represents the estimated filler content settlement ratio at which the sample has reached the peak filler content settlement. The discrepancy value of the respective ratios represents the relative emulsion stability of the samples by the following conclusions: a negative difference indicates that there is a possibility of earlier-than-expected oil leakage, whereas a positive difference indicates that leakage will occur past the point of average settlement. This value was calculated with the formula provided below:

$$
f_{\mathrm{a}}-f_{\mathrm{i}}=f_{d}
$$

where

- $f_{\mathrm{a}}$ : estimated percentage of the minimum filler content of the oil layer in the SPRG to achieve the required rheological state to leak through the concrete cracks;

- $f_{\mathrm{i}}$ : average percentage difference of the filler content of the oil layer and the original filler content over the evaluation period;

- $f_{d}$ : average filler content ratio discrepancy between average leaked oil sample filler content over the evaluation period and the IL day oil sample filler content.

\subsection{Comprehensive Results for Comparative Evaluation}

Comprehensive results on the four main properties discussed above were selected and are listed in Table 8. The table displays the results of the average mass of the oil leaked per samples (average of $l$ ), followed by the duration during which the samples leaked oil (average of $t_{1}$ ). Next, based on the filler content measurement of $r$ and $h$ for each sample, followed by their respective ratios to the original sample filler content $\left(f_{\mathrm{a}}\right.$ and $\left.f_{\mathrm{i}}\right)$, a discrepancy was derived to comparatively evaluate the filler content settlement stability of the samples.

With the results from Table 8, a radar chart with different scales was drafted. The areas of the four-sided figures drawn over the four difference axes provide a general guideline on the expected performance of the evaluated products on the overall oil leakage stability. Larger surface areas indicate lower filler content settlement stability. For the section evaluating the discrepancy between the average and IL filler content differences, values that went into the positive $(+)$ were not displayed in the radar chart.

In terms of comparative performance, it was shown that Samples A and B with the largest surface area displayed the lowest stability among the samples that leaked oil. Samples $C$ and $G$ with the smallest surface area displayed higher stability. Having shown no signs of leakage, Samples F and H were determined to be the most stable SPRG out of the tested samples in this demonstration. Refer to Figure 6 for details. 
Table 8. Comprehensive result of the evaluation demonstration.

\begin{tabular}{ccccc}
\hline $\begin{array}{c}\text { Sample } \\
\text { Types }\end{array}$ & $\begin{array}{c}\text { Avg. Leak } \\
\text { Mass (Avg. } l) \\
(\mathbf{g})\end{array}$ & $\begin{array}{c}\text { Period of Leak } \\
\left(\begin{array}{c}\left.\text { Avg. } \boldsymbol{t}_{\mathbf{1}}\right) \\
(\text { Days) }\end{array}\right.\end{array}$ & $\begin{array}{c}\text { Average Filler } \\
\text { Content \% Difference } \\
\left(f_{\mathbf{a}}\right) \mathbf{( \% )}\end{array}$ & $\begin{array}{c}\text { Discrepancy Obtained by } \\
\text { the Equation } f_{\mathbf{a}}-f_{\mathbf{i}}=f_{\boldsymbol{d}} \\
(\mathbf{\%})\end{array}$ \\
\hline A & 20.65 & 15 & 51.1 & $(-) 7.8$ \\
B & 9.12 & 13 & 59.9 & $(-) 11$ \\
C & 12.67 & 13 & 47.5 & $(+) 2.4$ \\
D & 13.59 & 13 & 36.9 & $(+) 1.9$ \\
E & 5.64 & 11 & 49.2 & $(-) 4.6$ \\
F & No Leak & No Leak & No Leak & No Leak \\
G & 11.83 & 15.6 & 42.8 & $(-) 0.7$ \\
H & No Leak & No Leak & No Leak & No Leak \\
\hline
\end{tabular}

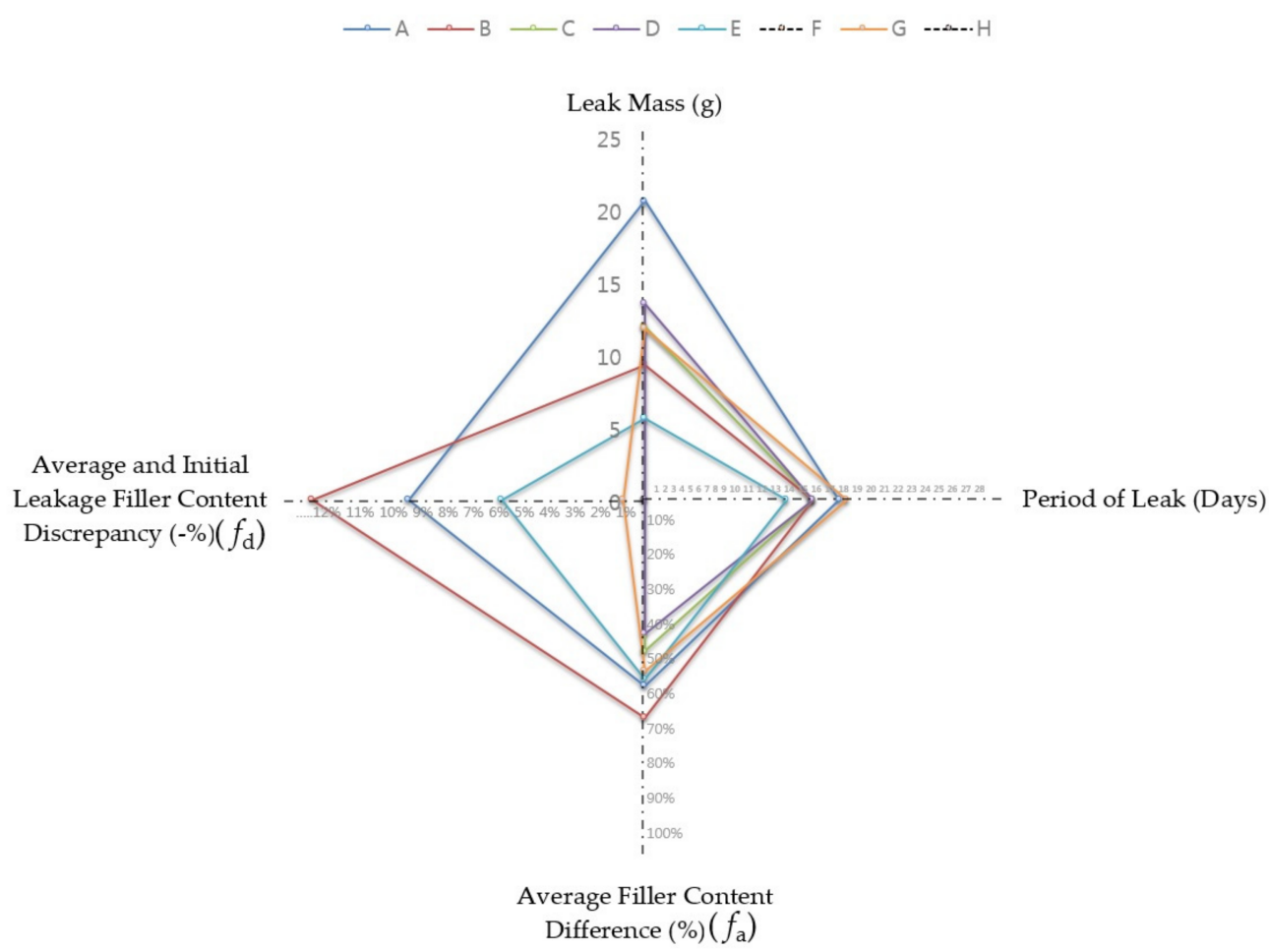

Figure 6. Comprehensive illustration of the evaluation results of the eight SPRG products.

\section{Conclusions}

While SPRG used as a part of CMBW systems are new and considered to be excellent waterproofing materials for below-grade concrete structures, there are products with unstable properties that consistently cause oil leakage problems. At the moment, standard evaluation criteria and evaluation methods are nonexistent for SPRG materials. Manufacturers verify their products in compliance with existing standard testing methods; based on these requirements, these products may seem to satisfy the performance criteria. However, when used in actual practice, faulty products lead to oil leakage problems, leading to a rise in maintenance and repair costs.

This study proposed an evaluation method with controls that more closely simulates the conditions found in below-grade concrete structures and incorporates an installation procedure of the tested SPRG. The demonstration was able to evaluate the SPRG products' susceptibility to oil leakage by measuring the amount, duration, and degree of overall filler content settlement, and provide an estimation of settlement stability by comparing the average filler contents to the filler content at the IL day. Next, the demonstration was able to provide a method to compare these factors with respect to stability performance. The evaluation method shown is only a demonstration, and requires more 
improvements in the future by incorporating more complex degradation factors into the evaluation criteria. It is hoped that through the development of a comprehensive evaluation method and criteria as was proposed in this study, future application of irregular SPRG can be prevented.

Author Contributions: S.-k.O., J.-s.P. and D.-b.K. conceived and designed the experiments; J.-s.P. and D.-b.K. performed the experiments; S.-k.O., J.-s.P., D.-b.K. and K.-h.O. analyzed the data; J.-s.P., D.-b.K. and K.-h.O. wrote the paper.

Acknowledgments: This research was supported by a grant (18RERP-B082204-05) from Residential Environment Research Program funded by Ministry of Land, Infrastructure and Transport of the Korean government.

Conflicts of Interest: The authors declare no conflict of interest. The founding sponsors had no role in the design of the study; in the collection, analyses, or interpretation of data; in the writing of the manuscript; or in the decision to publish the results.

\section{Abbreviations}

$\begin{array}{ll}\text { ASTM } & \text { American Standard of Testing and Materials } \\ \text { SPRG } & \text { Synthetic Polymerized Rubber Gels } \\ \text { BS } & \text { British Standards } \\ \text { CMBW } & \text { Composite Modified Bituminous Waterproofing } \\ \text { FC } & \text { Filler Content } \\ \text { IL } & \text { Initial Leakage } \\ \text { KS } & \text { Korean Industrial Standards } \\ \text { LH } & \text { KOREA LAND \& HOUSING CORPORATION }\end{array}$

\section{References}

1. Seo, W.I.; Kim, S.Y.; Kwak, G.S.; Oh, S.G. A Study on Complex Waterproofing Method Using Part of Joint Water-Tightness Improved Sheet; The Korea Institute of Building Construction: Seoul, Korea, 2004; Volume 7, pp. 1-6.

2. Chang, S.J. Advanced Technology of Waterproofing. J. Arch. Inst. Korea 2005, 49, 57-60.

3. Zakari, N.; Muhammad-Keyvanfar, A.; Muhd-Zaimi-Abd, M.; Shafaghat, A.; Mirza, J. Waterproof Performance of Concrete: A Critical Review on Implemented Approaches. Constr. Build. Mater. 2015, 101 Pt 1, 80-90.

4. Elsawy, M.M.; Taher, M.S.; Ebraheme, A.A.; Farag, R.K.; Saleh, A.M.M. Improvement Performance of Soft Bitumen for Coating Applications. Constr. Build. Mater. 2016, 128, 47-56. [CrossRef]

5. Oh, S.K.; Shim, J.S. Maintenance for Leakage due to Cracking in Concrete Structures-Guidelines for Repair of Water-Leakage Cracks in Concrete Structures. J. Korea Concr. Inst. 2011, 23, 47-52.

6. Ahn, D.S. A Study on the Physical Properties Change of Synthetic Rubber Polymer Gel by Using Stirring Screw Mixer. Master's Thesis, Seoul National University of Science and Technology, Seoul, Korea, 2015.

7. Song, J.Y.; Oh, K.H.; Kim, B.I.; Oh, S.K. Performance Evaluation of Waterproofing Membrane Systems Subject to the Concrete Joint Load Behavior of Below-Grade Concrete Structures. Appl. Sci. 2017, 7, 1147. [CrossRef]

8. Cuadri, A.A.; Carrera, V.; Izquierdo, M.A.; García-Morales, M.; Navarro, F.J. Bitumen Modifiers for Reduced Temperature Bitumens: A Comparative Analysis between Three Polymeric and Non-polymeric Additives. Constr. Build. Mater. 2014, 51, 82-88. [CrossRef]

9. Isacsson, U. A Compilation of Laboratory Methods for Studying Stability of Bitumen Emulsions. Mater. Struct. 1985, 18, 228-236. [CrossRef]

10. Palade, L.; Attane, P.; Camaro, S. Linear Viscoeslastic Behavior of Asphalt and Asphalt based Mastic. Rheol. Acta 2000, 39, 180-190. [CrossRef]

11. Deckard, C.; Hagerty, P.D. Rethinking Waterproofing for Subsurface Structures. In Forensic Engineering 2009: Pathology of the Built Environment, 1st ed.; Chen, S.-E., de Leon, A.D., Dolhon, A.M., Drerup, M.J., Parfitt, M.K., Eds.; American Society of Civil Engineers (ASCE): Washington, DC, USA, 2009; pp. 298-307.

12. Oba, K.; Hugener, M. Characterization of Polymer Modified Bituminous Roofing Membranes using Chromatography. Mater. Struct. 1995, 28, 534-544. [CrossRef]

13. Long, Y.; Dabros, T.; Hamza, H. Stability and Settling Characteristics of Solvent-diluted Bitumen Emulsions. Fuel 2002, 81, 1945-1952. [CrossRef] 
14. Oh, S.K.; Lee, J.Y.; Choi, S.M. An Experimental Study on the Highly Adhesive Composite Waterproofing Sheet using Reclaimed Rubber. J. Arch. Inst. Korea 2014, 16, 279-284.

15. ASTM D2170/D2170M-10. Standard Test Method for Kinematic Viscosity of Asphalts (Bitumens); ASTM International: West Conshohocken, PA, USA, 2010. [CrossRef]

16. Kim, H.S.; Kim, J.S.; Park, J.S.; Kim, D.B.; Park, W.G. A Research on Property Evaluation of Polymer-Modified Bitumen Waterproofing Sheet According to using Solven. J. Korean Recycled Constr. Resour. Inst. 2015, 15, 394-396.

(C) (

(c) 2018 by the authors. Licensee MDPI, Basel, Switzerland. This article is an open access article distributed under the terms and conditions of the Creative Commons Attribution (CC BY) license (http://creativecommons.org/licenses/by/4.0/). 